\title{
Corrigendum: An NGF-responsive element targets myo-inositol monophosphatase-1 mRNA to sympathetic neuron axons
}

Catia Andreassi, Carola Zimmermann, Richard Mitter, Salvatore Fusco, Serena Devita, Adolfo Saiardi \& Antonella Riccio Nat. Neurosci. 13, 291-301 (2010); published online 31 January 2010; corrected after print 19 April 2010

In the version of this article initially published, the last name of the fifth author was misspelled. The correct name is Serena De Vita. The error has been corrected in the HTML and PDF versions of the article.

\section{Corrigendum: Unmasking the tonic-aversive state in neuropathic pain}

Tamara King, Louis Vera-Portocarrero, Tannia Gutierrez, Todd W Vanderah, Gregory Dussor, Josephine Lai, Howard L Fields \& Frank Porreca

Nat. Neurosci. 12, 1364-1366 (2009); published online 27 September 2009; corrected after print 9 June 2010

In the version of this article initially published, a citation was inadvertently omitted. To correct this, "Attempts to measure the negatively reinforcing actions of MK-801, an NMDA receptor inhibitor, on chronic pain using CPP in a rat model of inflammation have been made, but the data were not conclusive $^{16 "}$ has been inserted following the first sentence in the fourth paragraph. A reference was also added to the reference list as follows:

16. Sufka, K.J. Pain 58, 355-366 (1994).

The error has been corrected in the HTML and PDF versions of the article.

\section{Corrigendum: Dopamine D2 receptors in addiction-like reward dysfunction and compulsive eating in obese rats}

Paul M Johnson \& Paul J Kenny

Nat. Neurosci. 13, 635-641 (2010); published online 28 March 2010; corrected after print 9 July 2010

In the version of this article initially published, two citations were inadvertently omitted. To correct this, the following sentence was inserted after the sixth sentence in the introduction (first paragraph, line 16): "In rats, both susceptibility to obesity and diet-induced obesity have been linked to deficits in mesolimbic dopamine signaling, with obesity-susceptible animals exhibiting reduced levels of D2 receptors ${ }^{50,51}$ ”"

These references have been added to the reference list as follows:

50. Geiger, B.M. et al. Evidence for defective mesolimbic dopamine exocytosis in obesity-prone rats. FASEB J. 22, 2740-2746 (2008).

51. Geiger, B.M. et al. Deficits of mesolimbic dopamine neurotransmission in rat dietary obesity. Neuroscience 10, 1193-1199 (2009).

The error has been corrected in the HTML and PDF versions of the article. 